\title{
Female aggression and male peace-keeping in a cichlid fish harem: conflict between and within the sexes in Lamprologus ocellatus
}

\author{
Bernhard Walter, Fritz Trillmich \\ Lehrstuh1 für Verhaltensforschung, Universität Bielefeld, PO Box 100131, D-33501 Bielefeld, Germany
}

Received: 10 July 1993 / Accepted after revision: 2 November 1993

\begin{abstract}
Summary. Conflicts of interest within and between the sexes are important processes leading to variability in mating systems. The behavioral interactions mediating conflict are little documented. We studied pairs and harems of the snail-shell inhabiting cichlid fish Lamprologus ocellatus in the laboratory. Due to their larger size, males controlled the resource that limited breeding: snail shells. Males were able to choose among females ready to spawn. Females were only accepted if they produced a clutch within a few days of settling. When several females attempted to settle simultaneously the larger female settled first. Females were least aggressive when guarding eggs. Secondary females were more likely to settle when the primary female was guarding eggs. In established harems females continued to be aggressive against each other. The male intervened in about $80 \%$ of female aggressive interactions. Male intervention activity correlated with the frequency of aggression among the females in his harem. The male usually attacked the aggressor and chased her back to her own snail shell. When a male was removed from his harem, aggression between females increased immediately and usually the secondary female was expelled by the primary female within a few days. Time to harem break-up was shorter the more mobile the primary females' young were and did not correlate with the size difference between harem females. Male L. ocellatus interfere actively in female conflict and keep the harem together against female interests. Female conflict presumably relates to the cost of sharing male parental investment and to the potential of predation by another female's large juveniles on a female's own small juveniles.
\end{abstract}

Key words: Lamprologus ocellatus - Polygyny - Sexual conflict - Male interference

\section{Introduction}

The "polygyny threshold" model (Verner 1964; Verner and Willson 1966; Orians 1969; Altman et al. 1977) has

Correspondence to: F. Trillmich long been a standard ecological explanation of the origin of polygyny. According to this model, females should choose a "breeding situation", i.e., a combination of the quality of a male and that of its territory, in which they can achieve the highest reproductive success (Wittenberger 1976). Important assumptions of the model are that (i) females are actually able to obtain the relevant information and (ii) are entirely free to settle in the preferred territory. However, these assumptions might not always be valid (see Davies 1989 for review). If limited time or high predation pressure makes searching for a good territory costly, or if a female approaching a male's territory is attacked by a resident female, the prospecting female may neither be able to get all the relevant information nor have the freedom to settle where she wants. In his discussion of the polygyny threshold model, Davies (1989) stressed that mating systems do not arise through female choice only, but should rather be regarded as different outcomes of conflicts of interest between and within the sexes (see also Davies 1992).

If conflicts of interest occur, they should be reflected in the behavior of individuals. In several studies of mating systems aggression between females (Yasukawa and Searcy 1982; Davies 1985; Stenmark et al. 1988; Breiehagen and Slagsvold 1988; Gowaty and Wagner 1988; Martin et al. 1990; Slagsvold et al. 1992) and conflicts of interest between males and females (Downhower and Armitage 1971; Alatalo et al. 1981; Gowaty 1981; Davies and Houston 1986; Arcese 1989; Davies 1992) were observed. In such a situation, one would expect males to intervene in conflicts between "their" females to stabilize a situation which benefits male fitness but reduces that of his females. Detailed observations documenting such behavioral conflict, however, are rare. This may partly be due to the fact that most of the studies were of passerine birds, which live in richly structured habitats, making detailed observations in the field difficult (Breiehagen and Slagsvold 1988; Slagsvold et al. 1992).

The facultatively polygynous cichlid fish Lamprologus ocellatus from Lake Tanganyika provides an ideal system for the analysis of the behavioral processes in such a 
conflict situation. Firstly, in the field, it lives on open sandy areas and occupies small territories of about 0.25 $1.2 \mathrm{~m}^{2}$ (Rossiter pers. comm.). The habitat and the necessary space can be provided reasonably naturally in captivity and the species is thus ideal for observation. Second, males monopolize snail shells and establish territories around these shells. In tanks, each male occupies one shell as a shelter and buries further shells completely into the sand (as apparently happens in the wild as well; W. Rossiter pers. comm.). If a gravid female approaches his territory, the male digs up one of his shells and permits a female to lay eggs in it. Males possessing more than two shells try to get more than one mate and may establish a harem (own observations; also found in the field, R. Bills, W. Rossiter pers. comm.). Food resources cannot be defended because the fish mainly feed on plankton which shifts through the water (Brichard 1989). Therefore, empty snail shells are the most important resource enabling breeding and the only one which allows monopolization. Consequently, the relevant breeding situation can easily be manipulated experimentally.

In this study we observed pairs and harems (i.e., one male breeding with two or more females in a more or less permanent association) under laboratory conditions and determined how the aggressive behavior of female $L$. ocellatus reflects conflict of interest among females breeding with one male and which behavioral options males have to reduce that conflict.

\section{Methods}

Experimental animals and materials. The experimental animals were the F1 and F2 generations descended from wild-caught $L$. ocellatus. They were initially raised by their parents until at least 20 days old and later kept in a 500-1 tank in a group of about 100 individuals of both sexes. The bottom of the tank was covered with a $1-\mathrm{cm}$ layer of fine sand. No snail shells were given, to avoid territoriality and breeding. The fish were fed daily with newly hatched Artemia salina. Water fleas, mosquito-larvae, or frozen adult $A$. salina were given on different days of the week. Water temperature was held constant at $26 \pm 1^{\circ} \mathrm{C}$

The bottom of the experimental tanks $(150 \times 50 \times 40 \mathrm{~cm})$ was covered $5 \mathrm{~cm}$ deep with sand. Because there were not enough Neothauma shells available, in which the fish nest in Lake Tanganyika (Fryer and Illes 1972), empty shells of Helix pomatia of comparable size were offered and readily accepted.

Establishment of pairs and harems. The experimental tanks contained one shell per individual. One male was put in each tank. A male was considered settled when it had occupied one shell, and dug all other shells (one in pairs, two in harems) into the sand. Males in this situation behave territorially when other male fish are introduced into the tank. After male establishment, one, or two in experimental harems, females were added. For harems, the three shells were arranged in a right-angled triangle such that the distance between the male's shell and each of its females' shells was $20 \mathrm{~cm}$, while the two females' shells were $25 \mathrm{~cm}$ apart. This corresponds to the distances which are possible between females in small natural territories and gives reasonably high interaction frequencies. Once a day, the animals in a tank were observed to determine when females settled. A female was considered settled when she either spawned in a shell or stayed at the same shell for at least 3 days. The latter criterion was used when spawning was not observed.
Observation of animals. Pairs and harems were observed for $15 \mathrm{~min}$ daily. In harems the female settling first was called the primary female, and the second to settle the secondary female. Observation of pairs started 1-6 days after settlement, on the day of first spawning. Eight harems were observed for 15 days until both females had finished one complete brood cycle. The brood cycle was divided into phases of 3-day length: $\mathrm{E}=$ egg phase; $\mathrm{LI}=$ first 3 days of wriggler-larval phase; $\mathrm{LII}=$ second 3 days of wriggler-larval phase; JI $=$ first 3 days with free-swimming juveniles, when they appear at the opening of the shell and take small plankton; JII = the following 3 days of the juvenile stage, when juveniles make more excursions outside and away from the shell.

In two further harems observations were made on 12 or more days spread over the brood cycle. These two harems were only included in calculations of behavior that does not depend on the stage in brood cycle, e.g. male interference in female aggression. Harem observation began on the day of the secondary female's first spawning. Observation ended after the young were free swimming for 6 days. The following behavior patterns were recorded for each individual in a pair or a harem:

Head-down display, threatening. One individual threatens another by spreading the unpaired fins and displaying the opercular spots in head-down position

Biting. In most cases a short bite into the flank of an individual; escalation to longer lasting mouth-fighting occurs rarely

Digging. All digging behaviors described by Haussknecht and Kuenzer (1991) serving to either dig a snail shell into the sand or keep its opening clear

Fanning. A female swims into its shell, stays a moment and quivers while moving slowly backwards out of the shell. This broodcare behavior ensures proper aeration and water exchange inside the snail shell

In aggressive behavior (head-down display, biting) the individual starting an interaction was called "initiative" and the one reacting to it "reactive". Only acts of the initiator were used for calculations.

Presentation of a strange female. To test how female aggressiveness changed over the brood cycle a strange female was presented in a transparent plastic tube (diameter: $10 \mathrm{~cm}$ ) to a breeding female for $15 \mathrm{~min}$ at five stages of the brood cycle. Interference by the male and, in harems, potentially by the second female was made impossible by confining the non-test animals in plastic tubes placed over their shells. The distance from the plastic tube to the nesting shell of the tested female was $30 \mathrm{~cm}$ in the first test series ( $n=10$ females; 6 monogamous and 4 in two harems) and $50 \mathrm{~cm}$ in the second ( $n=8 ; 4$ monogamous and 4 in two harems). The second test series was run after a 4-week break with eight of the individuals of the first test series. We measured how long and at what distance from her home shell $(10-\mathrm{cm}$ categories) the tested nesting female threatened the strange female in the tube.

Removal of harem males. To test how important the male was in maintaining harem stability, the male and his shell were removed from 11 breeding groups after each female had bred at least once with the male. The behavior of the females was recorded for 3 days before and after male removal. Daily checks were made to see whether or not both females were still occupying their shells until harem break-up or for 25 days after male removal, whichever occurred first.

\section{Results}

Pair and harem formation in L. ocellatus

Soon after the males had been put into an experimental tank, they began to dig in the shells. Males left only their 
living shell open and buried all others, completely closing their openings with sand. Females ready to spawn approached a male, showing a specific courting colouration with a dark back contrasting strongly with a very light belly. When the male accepted the female, he opened a covered shell and allowed the female to settle. Spawning always took place in the female shell. Females laid 14.5 eggs [median; first/third quartiles $(Q): 10 / 19 ; n=34$ ) in first clutches. Females that did not spawn soon after moving into a shell were chased away within 3 days (median; $n=7$; range: $1-6$ days). In two additional cases, females managed to stay at a shell without a brood for 9 and 10 days, respectively, before spawning for the first time. Also, females which lost their brood were chased away after 2 days (median, $n=11$; range: $1-5$ days). Thus, males clearly controlled female access to snail shells and, therefore, breeding opportunity.

This was possible because sexually mature females were significantly smaller and weighed less than males of the same age ( $U$-tests for size and mass, $P<0.001 ; n=32$ males, $n=38$ females). Median standard length of females was $2.75 \mathrm{~cm}(Q: 2.6 / 2.9 \mathrm{~cm})$, which was $80.9 \%$ of the males' length of $3.4 \mathrm{~cm}(Q: 3.3 / 3.5 \mathrm{~cm})$. Median body mass of the females was $0.64 \mathrm{~g}(Q: 0.57 / 0.74 \mathrm{~g})$ which was only $54.2 \%$ of the males' weight of $1.18 \mathrm{~g}(Q: 1.10 / 1.29 \mathrm{~g})$.

Once settled, females attached their eggs to the inner side of the shells' outermost whorl. After the 3-day eggphase, the wriggler-larvae hatched and lived from their yolk reserves for another 6 days (the larval phases I and II). About 10 days after egg-laying the young appeared at the opening of the shell (entering the juvenile phase), and began to forage for small plankton. They stayed in and around the females' shell until their mother's next spawning. Then some juveniles moved into the male's shell, while others left the territory.

\section{Settling of females in pairs and harems}

When females were added to a tank males did not immediately permit them to settle and usually chased them away from the area around the shell. In monogamous situations, males allowed females to settle within 9.5 days (median; $Q: 4 / 19$ days; $n=18$ ) after introduction to the tank. Primary females in harem situations settled after 8.5 days $(3 / 13 ; n=35)$, secondary females after 16.5 days $(10 / 28 ; n=35)$. The median difference between the settling time of the primary and the secondary female in a given harem was 7 days $(2 / 13 ; n=35)$. Primary females settled as fast as females in monogamous situations ( $U$ test, $P=0.60$ ), while secondary females settled significantly later than the primary females $(U$-test; $P<0.001)$ or females of monogamous pairs ( $U$-test; $P<0.02$ ). Six females, four in potential harem situations and two in monogamous situations, did not settle at all and were removed after 2 months. These are not included in the above calculations.

Delayed settlement of secondary females was related to aggressive interactions between the two females. Aggression set in even before the first female had settled. In
Table 1. Females settling as secondary female in relation to the primary female's brood cycle (horizontal) and the sequential number of her broods (vertical): based on 35 observed secondary female settlings

\begin{tabular}{lrrrrr}
\hline $\begin{array}{l}\text { Number of brood of } \\
\text { primary female }\end{array}$ & \multicolumn{5}{c}{ stage in brood cycle of primary female } \\
\cline { 2 - 6 } & E & L1 & L2 & J1 & J2 \\
\hline 1 & 11 & 5 & 5 & 1 & 2 \\
2 & 4 & 1 & - & 1 & - \\
3 & 2 & - & - & - & - \\
4 & 1 & - & 1 & 1 & - \\
\cline { 2 - 6 } total & 18 & 6 & 6 & 3 & 2 \\
\hline
\end{tabular}

32 out of 35 cases the heavier female settled first (binomial test, $P<0.001$ ). After the primary female had settled, she threatened the second female whenever the latter approached the snail shells. Secondary females were most likely to settle when the primary females had eggs or small fry in their shells, only few settled when the fry of the primary females was free swimming $\left(\chi^{2}=23.4\right.$; $d f=4 ; P<0.001)($ Table 1$)$.

Of 35 secondary females, 11 did not settle in the primary female's first brood cycle. Seven of these late-settling females established themselves at a shell when the primary female had eggs in her 2nd-4th brood cycle (Table 1). Summing over all brood cycles of the primary female in which secondary females became established, $51.3 \%$ of the secondary females settled when the primary female had eggs, $34.3 \%$ when she had larvae and only $14.3 \%$ when the primary female was caring for free swimming fry (Table 1).

How does settling of secondary females relate to the behavior of the primary females?

Settling of the secondary female may be related to changes in the behavior patterns of primary females over the brood cycle. We therefore studied how the behavior of breeding females changed over the brood cycle.

Digging occurred at a nearly constant frequency throughout the whole brood cycle (Friedman ANOVA, $n=16 ; \chi^{2}=5.4 ; P=0.25$, ns) (Fig. 1a), and its frequency did not differ between females in pairs and harems (Mann-Whitney $U$-tests, ns). Fanning peaked during the first 3 days $(E)$, when eggs were attached to the inner wall of the shell and then declined when the wrigglers hatched (Fig. 1b; Friedman ANOVA, $n=16 ; \chi^{2}=51.8$; $P<0.001$ ). Fanning frequencies of females in monogamous pairs $(n=10)$ and harems ( 16 females in 8 harems) did not differ (Mann-Whitney $U$-tests, ns).

Harem females threatened each other quite frequently. Overall, $52.7 \%$ (median; $Q: 39.7 / 76.6 \%$ ) of the aggressive interactions were begun by the primary female. In five harems the primary female was the more aggressive one, in three harems the secondary female. This indicates that there was no clearcut difference in aggressiveness be- 


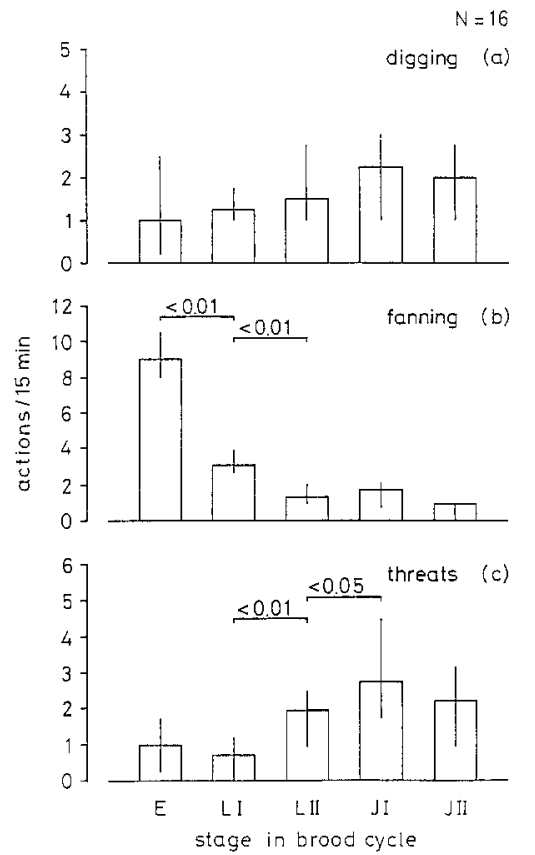

Fig. 1. Frequencies of a digging, $b$ fanning, and $\mathbf{c}$ threatening behavior of females over the course of the brood cycle. Stages in brood cycle of 3-day duration: $E=$ egg stage, $L I=$ first larval stage, $L I=$ second larval stage, $J I$ and $J I=$ first and second juvenile stage. $n=16$ nesting females in 8 harems. Medians and quartiles are given. Significant differences as indicated (Wilcoxon tests)

tween primary and secondary females. Apparently, the level of aggressiveness depended strongly on the stage in the brood cycle of a female. Head-down display between the two females of a harem occurred at a low rate when either female had small fry and increased when the fry of one of the two females entered the free-swimming phase (Fig. 1c; Friedman ANOVA, $n=16 ; \chi^{2}=21.8$; $P<0.001$ ). As Fig. 2 shows, it was always the female with more mobile young that showed more aggression in a harem. However, whether the secondary female had fry or young did not influence the primary female's level of aggressiveness which only changed with her stage in the brood cycle (Fig. 2; Wilcoxon tests, ns). The same applied to the secondary females (Fig. 2).

To determine more directly whether the level of female aggression against intruding females depended on her stage in the brood cycle, we set up an experiment, presenting a strange female in a plastic tube. The total time females spent threatening an intruder female changed over the brood cycle (Fig. 3) as described above for the harem situation. When an intruder was presented $30 \mathrm{~cm}$ from the nest shell, females with offspring in the egg-stage threatened for significantly less time (median: $67.8 \%$; $Q: 7.8 / 76.3 \%$ ) than females which were caring for larvae (LII: $84.7 \% ; 64.5 / 93.2 \%$ ) or for free swimming fry (JII: $91.9 \% ; 85.0 / 94.6 \%$ ) (Friedman ANOVA, $\chi^{2}=11.8$, $d f=4, P<0.02 ; n=10$ ).

When the intruding female was presented at $50 \mathrm{~cm}$ distance from the shell, the nesting females threatened significantly less time compared to the test series with $30 \mathrm{~cm}$ distance (Friedman ANOVA, $\chi^{2}=46.1, d f=9$, $P<0.001 ; n=8$ ). The differences were significant for all

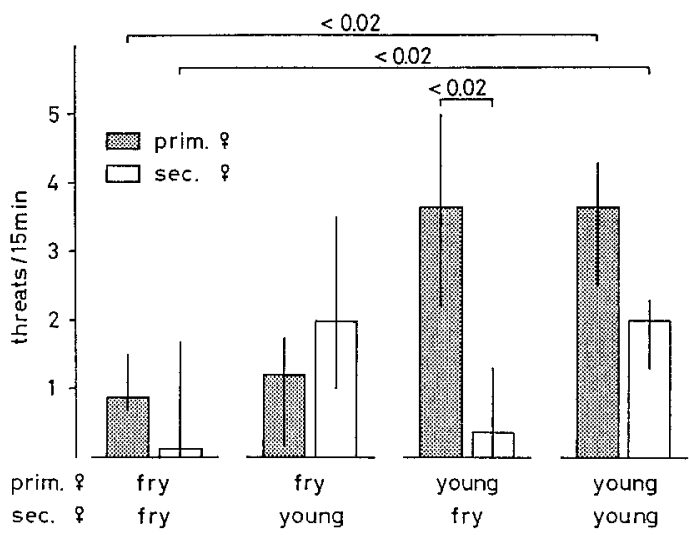

Fig. 2. Frequency of threats of primary (prim.) and secondary (sec.) females in 6 harems increases as young become more mobile. Labels on the abscissa give the developmental stage of the brood of the primary and secondary female at the time of measurement. Fry: larval stages I and II; young: juvenile stages I and II. Significantly differing frequencies (Wilcoxon tests) are indicated above the graph

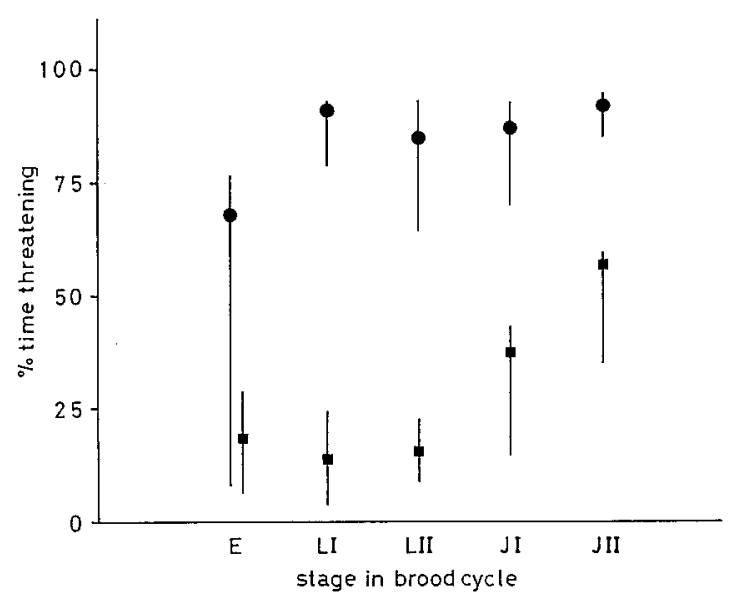

Fig. 3. Aggressive behavior by resident females toward strange females presented at $30 \mathrm{~cm}($ dots; $n=10)$ and $50 \mathrm{~cm}$ (squares; $n=8$ ) distance from the shell in relation to the brood cycle. Stages in brood cycle as in Fig. 1

phases except the egg phase (Wilcoxon tests, $P<0.05$; $n=8$ ). In the $50-\mathrm{cm}$ treatment, settled females threatened intruders for less time when guarding eggs $(18.3 \%$; $6.4 / 28.8 \%$ ) or larvae (LII: $15.44 \% ; 8.7 / 22.7 \%$ ) than when their fry was swimming outside the shell (JII: $56.7 \%$; $34.8 / 59.6 \%$ ) (Friedman ANOVA, $\chi^{2}=19.1, d f=4$, $P<0.001 ; n=8$ ) (Fig. 3). Besides the shorter duration of the threatening behavior during the egg-phase compared to the other phases, there was also a tendency to stay closer to the shell. Females spent less of the total threatening time directly at the tube in which the intruder female was presented when they had eggs than when they had free swimming fry (JII). However, variance among individuals was large and the effect was only significant in the 30-cm test series (Wilcoxon test, $P<0.05, n=10$; $50 \mathrm{~cm}$ distance: $P=0.11 ; n=8$ ). 


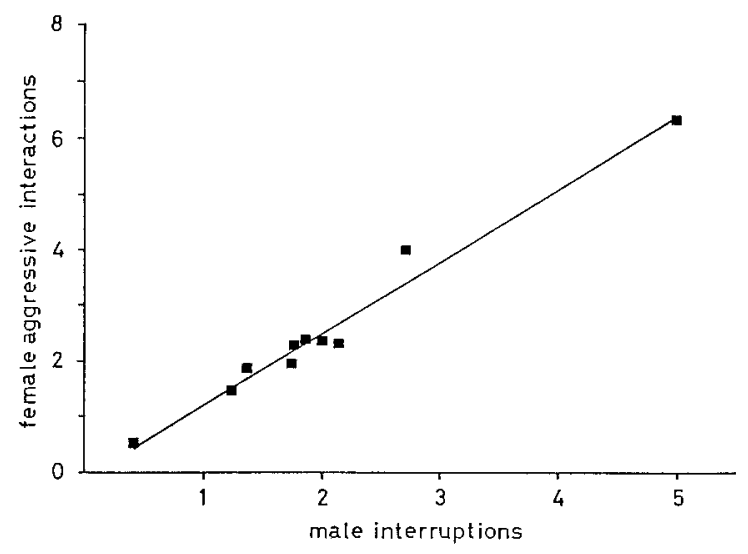

Fig. 4. Relationship between male intervention and female- female aggression. Data are means from at least twelve 15-min observation sessions during the first brood of 10 harems

\section{Male peace-keeping}

Averaged over the whole brood cycle females in established harems attacked each other 2.1 times per $15 \mathrm{~min}$ (range: $0.5-2.4 ; n=8$ harems). When one harem female threatened the other, the male usually at once spread his unpaired fins and swam towards the threatening female. The female showing most threats during an observation session was in $89.5 \%$ (median; $Q: 83.3 / 93.8 \% ; n=8$ harems) of the cases also the one which was most often threatened by the male, i.e. male intervention effectively functioned to protect the less aggressive female. Mostly the aggressor female stopped threatening and swam back to her shell. If the female did not stop and attacked the other female, the male interfered more aggressively and separated the females. The male often chased the aggressive female back to her shell and followed her whereupon the female showed fanning, even though in many cases she had no small fry in her shell.

The harem male interrupted $79.5 \%$ (median; range: $67.9-92.6 \% ; n=10$ harems) of the aggressive interactions between the two females in a harem. Males with more aggressive harem females intervened more often than males with more "harmonious" harems (Fig. 4). The median number of aggressive interactions per $15 \mathrm{~min}$ in a given harem and the number of interruptions of these interactions by the male were highly correlated (Fig. 4; interruptions $=-5.52+0.91 \times$ (number of female aggressive acts per $15 \mathrm{~min}$ ) $n=10 ; r=0.97 ; P<0.001$ ). In other words, the percentage of female aggressive interactions interrupted remained constant as female aggression increased. Even so, male intervention did not stop all female-female aggression, but only mitigated its effects in $80 \%$ of the interactions.

\section{Removal of the male}

Even given the ability of the male to interrupt $80 \%$ of female aggressive interactions, the remaining 20\% were sometimes enough to disrupt a harem. We therefore tested whether male intervention was really instrumental in maintainig harem stability. When we removed a male from his harem, the number of aggressive interactions between its two females increased dramatically: in the 3 days before male removal four (median; range 1-5) threats per $15 \mathrm{~min}$ were observed, whereas in the 3 days after the removal median frequency of aggressive interactions was 13 (11-19) (Wilcoxon test; $P<0.003 ; n=11$ ).

The number of aggressive interactions between the harem females in the 3 days before and after the male was removed were highly correlated $\left(r_{\mathrm{s}}=0.90 ; P<0.001\right.$; $n=11$ ), indicating that the increase in aggressive interactions after male removal was proportional to the level of aggressiveness in a given harem before the male was removed. After 4 days (median; $Q: 2-10$ days; $n=19$ ) the secondary, smaller of the two females was chased away from her shell by the larger primary female. A multiple regression analysis $(r=0.80 ; P<0.005 ; n=19)$ showed that the latency to harem break-up after male removal was negatively correlated with the primary females' stage in the broodcycle (5 stages each of 3 days duration; see methods) $(\beta=-0.80 ; P<0.001)$ and positivly correlated with the broodcycle of the secondary female $(\beta=0.51 ; P<0.02)$. Thus harem break-up occurred sooner the more mobile the primary female's brood was and the less mobile that of the secondary female. Time to harem disruption was not significantly correlated with the mass difference between the females $(\beta=-0.02$; ns) and also not with the number of broods $(1-4)$ they had reared together previously in the harem $(\beta=0.07$; ns).

\section{Discussion}

Male $L$. ocellatus play a very active role in moderating female conflict. Whereas in birds female interactions largely happen with the male acting as a bystander (Arcese 1989; Breiehagen and Slagsvold 1988; Leffelaar and Robertson 1985; Slagsvold et al. 1992; but see Hannon 1983 , 1984) male $L$. ocellatus almost continuously moderate female-female aggression. Male birds apparently avoid female conflict mostly by keeping females spatially separate, as in willow ptarmigan (Hannon 1983) or the case of polyterritoriality in the pied flycatcher (Slagsvold et al. 1992). This option is not available to the male fish who has to keep both females close by to insure his paternity for broods of both females over a potentially long sequence of breeding cycles.

We first discuss actual conflict behavior in L. ocellatus, which is only poorly known from bird examples, and then ask for its ultimate causes comparing the L. ocellatus case to what is known from birds.

\section{Conflict between females during settlement}

The larger female always settled before the smaller one. Males did not play an obvious role in this settlement sequence even though one would expect them to prefer the larger female as she would produce more eggs. The settlement of a second L. ocellatus female in the territory of a male occurs against the aggressive resistance of the 
primary female who tries, similarly to female birds (Hannon 1984; Yanagisawa 1987; Martin et al. 1990), to maintain the monogamous situation, causing delayed settlement of a secondary female. The intensity of aggressive resistance of the primary female depends on her stage in the brood cycle. A second female appeared more likely to settle when the primary female had eggs or small larvae in her shell (Table 1). However, there were also fewer females to settle during the later stages of the brood cycle, and the females left may have been a biased sample of females. To check for such an effect, we should have added females at various stages of the primary female's brood cycle, which is difficult to achieve because females need time to become accustomed to the situation in a tank before they ever attempt to settle.

A brood cycle dependent level of aggressivity against intruder females was also shown in some studies on passerine birds (Breiehagen and Slagsvold 1988; Gowaty and Wagner 1988) where resident females were most aggressive before and during egg-laying and showed little aggression during the incubation period and after the nestlings had fledged. In these cases as in other well documented ones (Pinxten and Eens 1990), females usually do not breed repeatedly in the same polygynous situation (i.e. with all the same interaction partners) so that a resurgence of female-female conflict is not observed. This contrasts strongly with $L$. ocellatus in which females must rear their young in continuous competition with the same other female living in the same territory over many brood cycles.

Heightened aggression during egg-laying in birds has been interpreted as defense against egg dumping and protection of nest sites from usurpation by intruder females. Although there are observations in L. ocellatus that larvae were transferred between two females in a harem and that young changed regularly from one to the other female (pers. obs.), there are no hints that egg dumping occurs (i.e. that eggs are laid into another female's shell). Female aggression against intruder females (Fig. 3) presumably functions mainly to protect against shell usurpation and thereby incidentally also prevents egg dumping. Another factor, which plays no role in the bird examples, is that non-breeding individuals of $L$. ocellatus prey on small juveniles of their own species (pers. obs.). Thus, an intruder female may be both a competitor for the breeding site and a predator of young. This may explain why the area which females defend against intruders changes over the brood cycle: females which care for eggs or larvae need not leave the shell because the larvae are inside and the shell itself is better defended when the opening is shielded. In contrast, mothers of free-swimming fry can best prevent intruders from predating young by defending a larger area around a shell.

\section{Conflict between females in an established harem}

The level of aggression between the females of an established $L$. ocellatus harem depends on the stage in the brood cycle of the females (Fig. 2), similar to the pattern of aggression observed for the settlement of secondary females (for birds compare Hobson and Sealy 1989; Martin et al. 1990). Within a harem, the other female's stage in the brood cycle is of minor importance for the level of aggressivity shown by a female. This is confirmed by the experiments with intruder females, where primary and secondary females did not differ in aggression levels from monogamously paired females or from each other.

Further evidence for a conflict of interest between the females in a harem was provided by the male removal experiments. Harem breeding is against the interest of the primary female. However, joining the harem serves the interest of the secondary female, and from this arises the conflict of interest between the females. Once a harem has become established, the male keeps it together against the interest of the females, both of which would presumably prefer to be the only female in the territory. Within a few days of male removal, aggression between females escalated and the harem broke up. The correlation of time to harem break-up with the brood cycle of the females shows once more the significance of the stage in the brood cycle for the level of aggressivity of a female. Females with free-swimming fry defend a larger area around their shell and are, therefore, more likely to interfere with the second harem female. Without exception, the smaller (lighter) female was expelled from her shell, demonstrating that body mass strongly correlates with resource holding potential, as was also shown for male $L$. ocellatus (Walter 1991).

\section{Ultimate causes of female-female conflict}

The phenotypic conflict between harem females must ultimately be caused by a loss of fitness when more than one female resides in a male's territory. Such fitness costs for polygynously mated females have been shown in several bird studies (Simmons 1989; Alatalo et al. 1990; Davies 1992). Resource depression and lowering of the male's parental investment in their own young are the selective processes causing bird females to resist polygynous mating of their mate.

Presently, we can suggest three potential fitness costs to polygynously paired $L$. ocellatus females which could explain why females resist the settlement of a second female and remain aggressive against each other once a secondary female becomes established:

1. Male parental investment is likely to become diluted when a second female settles in his territory. The male allows juveniles to stay in his shell when a female evicts them from her shell after laying another clutch. Young of previous broods may stay in and near the male's shell for up to several weeks longer. Because the shell of a male can only give shelter to a limited number of young, the number of young which a female in a harem gets into the male's shell is reduced by every additional female which settles and produces young on his territory. Investigations on the dispersal of juvenile $L$. ocellatus indicate that young in a harem have to leave the territory earlier than young in a monogamous situation (Walter in prep.).

2. Cannibalism occurs among young of different cohorts. Older young were observed to chase, bite and 
sometimes even eat smaller juveniles when the latter begin to make excursions outside the shell. Thus, a second female produces young that potentially damage own young or may even eat them. Females of $L$. ocellatus are sometimes very aggressive towards bigger juveniles, but we never observed a breeding female or male to cannibalize young. Thus, predation of young by females within a harem cannot explain the continuing aggression between the two females after the second female has settled.

3 . Females may try to chase the other female away to get the shell as an additional shelter for own young. Three cases were observed, but only in monogamous situations, in which a female used two shells as shelters for her young. However, this factor is less important since males usually close the opening of all shells uninhabited by adult females.

Resource depression seems highly unlikely to be an important factor since females as well as young feed on planktonic prey which more or less continuously drifts through the territory and does not constitute a defensible resource. Local depletion of planktonic prey by the aggregation of young, however, cannot be entirely excluded. This needs to be tested in the field.

Why do females agree at all to settle as secondary females if this involves considerable fitness costs? Because of their greater body mass male L. ocellatus dominate access to snail shells which are necessary for breeding. Additionally, by burying uninhabited shells they reduce resource availability. This was also observed in the field (W. Rossiter, pers. comm.) and perhaps reduces the cost of resource defense. Intense competition among males may thus lead to a strongly skewed operational sex ratio, with more females than breeding shells in the population, forcing females to accept whatever breeding opportunity offers itself. Female choice of a breeding partner may therefore be of minor importance and the main decision females make may be whether or not to breed. Given this situation, smaller females will be forced to accept secondary status if they want to breed at all.

\section{Conflict between the sexes}

Male interference in female aggression in established harems reflects the differences of interest between the sexes. This phenomenon is known from birds (Davies 1992) and mammals, especially primates (Bernstein and Ehardt 1986; Ehardt and Bernstein 1992), but has not previously been reported from fish. In L. ocellatus, the male has to intervene frequently in aggressive interactions between his females to maintain the harem situation. Because the more aggressive females were attacked more frequently by the male, the male in effect protects that female in his harem which is at its most vulnerable stage of the brood cycle. The mechanism responsible for this apparently clever intervention strategy could follow a simple rule, e.g., attack the female which is more distant from the shell (most likely the attacker) and oriented towards it (aggressor normally oriented head towards the shell, defender with tail towards shell). This simple rule would allow the male to detect which female is the aggressor and interfere accordingly.

The influence of male intervention on harem stability is obvious from the male-removal experiments. The bigger primary females dominated the situation when the male was removed. Nevertheless, the time to harem disruption was not correlated with absolute difference in body mass of the two females. Harem disruption occurred earlier the more mobile the fry of the primary and the less mobile the fry of the secondary female was, again pointing to the importance of the stage in the brood cycle for female aggressiveness.

One of the main assumptions of the polygyny threshold model thus does not apply in the case of the social system of $L$. ocellatus. Even though males control resources unevenly, secondary females are not free to settle, because of the aggressive resistance of resident females. Males control the limiting resource and are therefore able to choose among females willing to breed. Only reproducing females are allowed by the male to settle or to stay at a shell. Polygyny is forced upon the females by male control of the resource. As in birds, in L. ocellatus one would predict higher fitness for polygynously paired males than for monogamously paired ones and the opposite for females. Experiments to test this prediction are planned.

Acknowledgements. BW was supported by the Deutsche Studienstiftung. We would like to thank R. Diesel, T. Meijer, H.H. Schwarz, $T$. Slagsvold and three anonymous referees for critically reading the manuscript and many constructive suggestions (even though we did not follow all of them). We thank E. Geißler for drawing the graphs. $\mathrm{R}$. Bills and W. Rossiter kindly provided information on the behavior of the fish in the field.

\section{References}

Alatalo RV, Carlson A, Lundberg A, Ulfstrand S (1981) The conflict between male polygamy and female monogamy: the case of the pied flycatcher, Ficedula hypoleuca. Am Nat 117:738-753

Alatalo RV, Lundberg A, Rätti O (1990) Male polyterritoriality and imperfect female choice in the pied flycatcher Ficedula hypoleuca. Behav Ecol 1:171-177

Altmann SA, Wagner SS, Lenington S (1977) Two models for the evolution of polygyny. Behav Ecol Sociobiol 2:397-410

Arcese P (1989) Intrasexual competition and the mating system in primarily monogamous birds: the case of the song sparrow. Anim Behav 38:96-111

Bernstein IS, Ehardt CL (1986) Selective interference in rhesus monkey (Macaca mulatta) intragroup agonistic episodes by age-sex class. J Comp Psychol 100:380-384

Breiehagen T, Slagsvold T (1988) Male polyterritoriality and female-female aggression in pied flycatchers Ficedula hypoleuca. Anim Behav 36:604-605

Brichard P (1989) Book of cichlids and all the other fishes of Lake Tanganyika. TFH Publ, Neptune, New Jersey

Davies NB (1985) Cooperation and conflict among dunnocks Prunella modularis in a variable mating system. Anim Behav 33:628-648

Davies NB (1989) Sexual conflict and the polygamy threshold. Anim Behav 38:226-234

Davies NB (1992) Dunnock behaviour and social evolution. Oxford University Press, Oxford

Davies NB, Houston AI (1986) Reproductive success of dunnocks Prunella modularis in a variable mating system. II. Conflict of interest among breeding adults. J Anim Ecol 55:139-154 
Downhower JF, Armitage KB (1971) The yellow-bellied marmot and the evolution of polygamy. Am Nat 105:355-370

Ehardt CL, Bernstein IS (1992) Conflict intervention behaviour by adult male macaques: structural and functional aspects. In: Harcourt AH, Waal FB de (eds) Coalitions and alliances in humans and other animals. Oxford University Press, Oxford, pp 83-111

Fryer G, Illes TD (1972) The cichlid fishes of the Great Lakes of Africa. Their biology and evolution. TFH Publ, Neptune, New Jersey

Gowaty PA (1981) Aggression of breeding eastern bluebirds (Sialia sialis) toward their mates and models of intra- and interspecific intruders. Anim Behav 29:1013-1027

Gowaty PA, Wagner SJ (1988) Breeding season aggression of female and male eastern bluebirds (Sialia sialis) to models of potential conspecific and interspecific egg dumpers. Ethology 78:238-250

Hannon SJ (1983) Spacing and breeding density of willow ptarmigan in response to an experimental alteration of sex ratio. $J$ Anim Ecol 52:807-820

Hannon SJ (1984) Factors limiting polygyny in the willow ptarmigan. Anim Behav 32:153-161

Haussknecht T, Kuenzer P (1991) An experimental study of the building behaviour sequence of a shell-breeding cichlid fish from lake Tanganyika (Lamprologus ocellatus). Behaviour 116:127142

Hobson KA, Sealy SG (1989) Female-female aggression in polygynously nesting yellow warblers. Wilson Bull 101:84-86

Leffelaar D, Robertson RJ (1985) Nest usurpation and female competition for breeding. Wilson Bull 97:221-224

Martin K, Hannon SJ, Lord S (1990) Female-female aggression in white-tailed ptarmigan and willow ptarmigan during the preincubation period. Wilson Bull 102:532-536
Orians GH (1969) On the evolution of mating systems in birds and mammals. Am Nat 103:589-603

Pinxten R, Eens M (1990) Polygyny in the European starling: effect on female reproductive success. Anim Behav 40:1035-1047

Simmons R (1989) How polygynous female northern harriers Circus cyanaeus choose their mates and why they are deceived. In: Meyburg B-U, Chancellor RD (eds) Raptors in the modern world. World Working Group on Birds of Prey, Berlin, pp 243246

Slagsvold T, Amundsen T, Dale S, Lampe H (1992) Female-female aggression explains polyterritoriality in male pied flycatchers. Anim Behav 43:397-407

Stenmark G, Slagsvold T, Lifjeld JT (1988) Polygyny in the pied flycatcher Ficedula hypoleuca: a test of the deception hypothesis. Anim Behav 36:1646-1657

Verner J (1964) The evolution of polygamy in the long-billed marsh wren. Evolution 18:252-261

Verner J, Willson MF (1966) The influence of habitats on mating systems of North American passerine birds. Ecology 47:143147

Walter B (1991) Conflict of interest in a harem: behavioural observations on the snail cichlid Lamprologus ocellatus (Steindachner 1909). Verh Dtsch Zool Ges 84:333-334

Wittenberger JF (1976) The ecological factors selecting for polygyny in altricial birds. Am Nat 110:779-799

Yanagisawa Y (1987) Social organization of a polygynous cichlid Lamprologus furcifer in lake Tanganyika. Jpn J Ichthyol 34:82 90

Yasukawa K, Searcy WA (1982) Aggression in female red-winged blackbirds: a strategy to ensure male parentál investment. Behav Ecol Sociobiol 11:13-17 